\title{
Determinants of postnatal care utilization in urban community among women in Debre Birhan Town, Northern Shewa, Ethiopia
}

Banchalem Nega Angore', Efrata Girma Tufa ${ }^{2,4}$ and Fithamlak Solomon Bisetegen ${ }^{3,5^{*}}$ (D)

\begin{abstract}
Background: Reducing maternal mortality and improving maternal health care through increased utilization of postnatal care utilization is a global and local priority. However studies that have been carried out in Ethiopia regarding determinants are limited. So This study aims to assess the magnitude of postnatal care utilization and its determinants in Debre Birhan Town, North Ethiopia.

Methods: A community-based cross-sectional study was conducted from March 1 to April 25, 2015, in Debre Birhan Town. Data were collected through face-to-face interviews using structured pre-tested questionnaires. The data were entered and cleaned in Epi Info version 3.5 and analyzed using SPSS version 20. Bivariate and multiple logistic regression analyses were used. Variable with $p$ value less than or equal to 0.2 at bivariate analysis were entered into multiple logistic regression. Significance was declared at 0.05 in multiple logistic regressions and considered to be an independent factor.
\end{abstract}

Result: From the total respondents, we found that 327 (83.3\%) mothers utilized the postnatal care services. Single mothers were less likely to utilize postnatal care services than those mothers who are married and live together [adjusted odds ratio $(A O R)=0.06,95 \% \mathrm{Cl}(0.01,0.45)]$. This study revealed that respondent's knowledge about postnatal care services is an important predictor of postnatal care utilization $[\mathrm{AOR}=0.03,95 \% \mathrm{Cl}(0.00,0.44)]$ and mothers who delivered in a health care facility were more likely to receive PNC than mothers who did not deliver in a health care facility $[\mathrm{AOR}=0.65,95 \% \mathrm{Cl}(0.58,0.94)]$.

Conclusion: The postnatal care utilization rate in Debre Birhan town was 83.3\%. Marital status, maternal knowledge, and place of delivery were predictors of postnatal care service utilization. So specific attention should be directed towards the improvement of women's education since the perception of the need for PNC services were positively correlated with the mother's education.

Keywords: Women, Postnatal care utilization, Determinants, Debre Birhan, Ethiopia

\footnotetext{
* Correspondence: fitha2007@yahoo.com

${ }^{3}$ Department of Medical Laboratory, College of Health Sciences and

Medicine, Wolaita Sodo University, Po.box 138, Wolaita Sodo, Ethiopia

${ }^{5}$ School of Medicine, College of health science and Medicine, Wolaita Sodo

University, Wolaita Sodo, Ethiopia

Full list of author information is available at the end of the article
}

(c) The Author(s). 2018 Open Access This article is distributed under the terms of the Creative Commons Attribution 4.0 International License (http://creativecommons.org/licenses/by/4.0/), which permits unrestricted use, distribution, and reproduction in any medium, provided you give appropriate credit to the original author(s) and the source, provide a link to the Creative Commons license, and indicate if changes were made. The Creative Commons Public Domain Dedication waiver (http://creativecommons.org/publicdomain/zero/1.0/) applies to the data made available in this article, unless otherwise stated. 


\section{Background}

According to WHO, the postnatal, also called postpartum, is the period begins from 1-h after the delivery of the placenta and continues until the 6 weeks (42 days) [1]. Postnatal care (PNC) is regarded as the most important maternal health care service for the prevention of physical and cognitive impairments as well as disability resulting from a postnatal causes [2, 3]. Care during this period is critical for the health and survival of both the mother and the newborn [4].

In 2015, more than 300 million women suffered from pregnancy-related complications and disabilities. Eight hundred thirty women also died each day from pregnancy-related complications [5]. In the year 2015, it was estimated that roughly 303,000 women died due to pregnancy-related complication in low-resource settings [6]. As a result of inadequate postnatal care services, more than two thirds of maternal and newborn deaths occur. The majority of maternal deaths (62\%) occur in the postnatal period and more than half of these takes place within a day of delivery [7].

In Ethiopia, maternal mortality ratio (MMR) in Ethiopia is 676 per 100,000 which is significantly higher than the developing country rate and the global rate. The MMR of Ethiopia contrasts with that of UK and the global average, which is 12 and 400, respectively. The national average of the postnatal coverage is only $8 \%$ [8]. Compared to antenatal care and skilled attendance at birth, the postnatal care in Ethiopia has been described as a neglected area of maternity care even in safe motherhood programs in Ethiopia [9].

The risk of maternal death is highest close to birth; it then decreases over the subsequent days, weeks and months. Of postpartum deaths, $45 \%$ occur within 1 day of delivery, more than $65 \%$ within 1 week, and in excess of $80 \%$ within 2 weeks [10].

Studies indicated that the extent of PNC services utilization was associated with factors like maternal age, educational level, occupation, place and mode of delivery, number of pregnancies, awareness about obstetricrelated danger sign, and awareness about PNC services. The determinants of utilization of PNC services are not also the same across different cultures and socioeconomic status within a society [11-16].

Even though most of the maternal deaths happen during postpartum period, in developing countries, there are a small number of women turning up for PNC than ante-partum and intra-partum care [17].

The impact of the low coverage of postnatal care in Ethiopia is reflected as high neonatal deaths, as well as maternal morbidity and mortality. As a result, the nation did not achieve the millennium development goals (MDGs) that are related to child and maternal mortality (MDG 4 and MDG 5) [18]. The low PNC coverage is a challenge that needs to be addressed [19].

As per the 2015 Ethiopia Demographic and Health Survey (EDHS), Debre Birhan town was a model city for Amhara region to improve the postnatal service care and to achieve the MDG goals. As a result, investigating determinants of under-utilization of postnatal services is a worthy endeavor. By investigating the determinants, this study fills the empirical research gap. This study hypothesized that the PNC coverage in Debre Birhan town is higher than the EDHS national coverage.

\section{Methods}

Study design

A community-based cross-sectional study design was used.

\section{Study period and area}

The study was conducted from March 1 to April 25, 2015, in Debre Birhan town, North Shoa, 130 km North East of Addis Ababa. The town is administratively divided into nine Kebeles. According to the 2007 census report, Debre Birhan town has a total population of 65,214 of which 33,556 are females. Out of the 33,556 females, the estimated number of women of childbearing age (15-49 years) is 21,792 . The town has two hospitals, four health centers, nine health posts, and six pharmacies.

\section{Eligibility criteria}

All mothers who gave birth prior to 6 weeks to 12 months of the survey were included whereas mothers who gave birth less than 6 weeks to data collection period were excluded.

\section{Sample size and sampling techniques Sample size}

The sample size was determined by using a single population proportion formula considering the following assumptions: $P=8 \%$ taken [9], level of significance to be 95\% $(\alpha=0.05), Z \alpha / 2=1.96$, absolute precision or margin of error to be $4 \%(d=0.04)$, and design effect $=2$

$$
\begin{aligned}
n & =(\mathrm{Za} / 2)^{2} \times P(1-P) / d^{2} \\
& =(1.96)^{2} \times 0.08 \times 0.92 /(0.04)^{2} \times 2=354
\end{aligned}
$$

By taking 10\% of non-response rate, 390 mothers were included.

\section{Sampling procedure}

A multistage sampling procedure was used to select from the total of nine Kebeles. Four Kebeles were selected using simple random sampling technique, and in each selected Kebele, the total sample was proportionally 
distributed to the four Kebeles. Finally, the households from each Kebele were selected using systematic sampling. The sampling frame of the households (owners) were prepared by using the mother list of the health extension workers.

\section{Data collection tools and techniques}

For data collection, a face-to-face interview was performed using a structured pre-tested questionnaire. Four nurses were used to collect data. Two midwives from Debre Birhan University Hospital were assigned to supervise the data collection process. Both the data collectors and supervisors underwent a 2-day intensive training before the actual work about the aim of the study, procedures, data collection techniques, the art of

Table 1 Socio-demographic characteristics of the study participants in Debre Birhan Town, North Shewa, $2015(n=390)$

\begin{tabular}{|c|c|c|c|}
\hline Variables & & Number & Percent \\
\hline \multirow[t]{4}{*}{ Religion } & Orthodox Christian & 354 & 90.8 \\
\hline & Muslim & 22 & 5.6 \\
\hline & Protestant & 11 & 2.8 \\
\hline & Other & 3 & 0.8 \\
\hline \multirow[t]{3}{*}{ Ethnicity } & Amhara & 375 & 96.2 \\
\hline & Oromo & 14 & 3.6 \\
\hline & Other & 1 & 0.25 \\
\hline \multirow[t]{4}{*}{ Marital status } & Married & 328 & 84.1 \\
\hline & Unmarried & 31 & 7.9 \\
\hline & Divorced & 24 & 6.2 \\
\hline & Widowed & 7 & 1.8 \\
\hline \multirow[t]{4}{*}{ Educational status } & Illiterate & 45 & 11.5 \\
\hline & Grades 1-8 & 162 & 41.5 \\
\hline & Grades 9-12 & 122 & 31.3 \\
\hline & $12+$ & 61 & 15.6 \\
\hline \multirow[t]{3}{*}{ Occupation status } & Housewife & 196 & 50.3 \\
\hline & Self-employed & 138 & 35.4 \\
\hline & Government employee & 56 & 17.1 \\
\hline \multirow[t]{4}{*}{ Husband's education } & Illiterate & 16 & 4.1 \\
\hline & Grades1-8 & 119 & 30.5 \\
\hline & Grades 9-12 & 52 & 39 \\
\hline & $12+$ & 103 & 26.4 \\
\hline \multirow[t]{3}{*}{ Family size } & $1-3$ & 130 & 33.3 \\
\hline & $4-6$ & 231 & 59.2 \\
\hline & $7-10$ & 27 & 6.5 \\
\hline \multirow[t]{4}{*}{ Average monthly income } & $<500$ & 108 & 27.7 \\
\hline & $501-1500$ & 201 & 51.5 \\
\hline & $1501-2500$ & 60 & 15.4 \\
\hline & $>2501$ & $21(5.4)$ & \\
\hline
\end{tabular}

interviewing, ways of collecting the data, and clarification were given.

\section{Variables of the study}

Dependent variables: utilization of postnatal care service.

\section{Independent variables}

- Socio-demographic characteristics: age, marital status, religion, parity, culture, income, educational status, occupation, husband's education, and husband's occupation

- Environmental factors: distance from nearby health institutions

- Behavioral/clinical factors: knowledge, history of antenatal care, type of delivery, and place of delivery

\section{Data quality control}

Questionnaire was pre-tested in one of the Keble other than the selected Kebeles on 5\% of participants. Every day after data collection, questionnaires were reviewed and checked for completeness and relevance by the supervisors and a principal investigator, and the necessary feedback were offered to data collectors in the next morning.

Table 2 Obstetrics characteristics of study participant in Debre Birhan town, North Shoa, Ethiopia $2015(n=390)$

\begin{tabular}{lll}
\hline Variables & Number & Percent \\
\hline Age at first pregnancy & 23 & 5.9 \\
$<18$ & 365 & 93.6 \\
$18-35$ & 2 & .5 \\
35 and above & & \\
Gravidity & 154 & 39.5 \\
1 & 215 & 55.1 \\
$2-4$ & 21 & 5.4 \\
$\geq 5$ & & \\
Number of live births & 162 & 41.5 \\
1 & 211 & 54.1 \\
$2-4$ & 17 & 4.4 \\
$\geq 5$ & & 96.2 \\
Ever had abortion & 275 & 3.9 \\
No & 15 & 3.1 \\
Yes & & \\
Ever had still birth & 380.9 \\
No & 12 & 2.6 \\
Yes & & \\
Ever had neonatal death & & \\
Yes & & \\
No & & \\
\hline
\end{tabular}




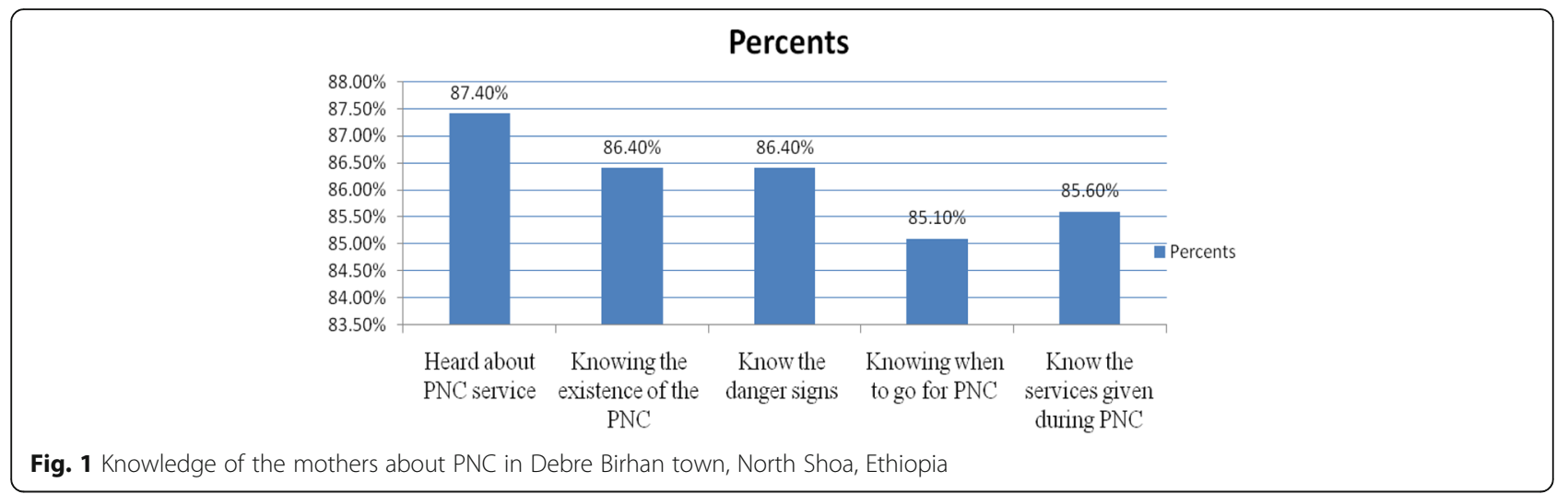

\section{Data processing and analyses}

Data were entered into Epi Info version 5.3.1 statistical software and then transferred to statistical package for social science (SPSS) windows version 20.0 for further analysis. Bivariate analysis was used primarily to check which independent variables had an association with a $p$ value less than (0.25\%) that of the dependent variable. Variables found to have association were entered into a multivariate analysis for controlling the possible effect of confounders, and finally, the variables which had a $p$ value less than 0.05 were taken as a statistically significant association which was identified on the basis of an OR with 95\% CI.

\section{Results}

\section{Socio-demographic characteristics}

A total of 390 mothers were participated in the study. The mean age of the respondents was $28.65 \pm 1.35$ years, and the age ranges from 15 to 46 years. Concerning marital status, the majority of the respondents 328 (84.1\%) were married. Majority of the respondent were Orthodox Christians amounting to 354 (90.6\%). Regarding educational status, $162(41.5 \%)$ had attended at least primary school. By ethnic composition, most of the respondents were Amhara 375 (96.2\%) (Table 1).

\section{Obstetrics characteristics of the respondents}

The vast majority $(365,93.6 \%)$ of the women were pregnant between the age of 18 and 35 years. It is only $23(5.9 \%)$ who were below 18 years of age when they were first pregnant with a mean age at first pregnancy being $23.1 \pm 3.9$ years. Of all the respondents, 154 (39.5\%) women had only one pregnancy. The majority of the women $(215,55.1 \%)$ reported that they had two to four pregnancies (Table 2).

\section{Knowledge of the respondents}

About 341 (87.4) mothers had heard about PNC services, 337(86.4\%) knows the danger signs during postnatal period, and $85.6 \%$ of them know the types of services which are given during PNC (Fig. 1). Concerning knowledge about the timing of PNC service, 199 (51\%) visited the PNC service 8-42 times, 81 (20.8\%) visited 4-7 times, and the rest (52, 13.3\%) visited $2-3$ times.

\section{Environmental, clinical, and behavioral factors}

Majority of the respondents gave birth at health institutions 354 (90.8\%). Three hundred thirty (84.6\%) responded the PNC service is easy to get. More than half

Table 3 Environmental, clinical, and behavioral factors of the respondents in Debre Birhan town, North Shoa, Ethiopia 2015 $(n=390)$

\begin{tabular}{llll}
\hline Name of the variable & Frequency & $\begin{array}{l}\text { Percent } \\
(\%)\end{array}$ & $p$ value \\
\hline Place of delivery & 36 & 9.2 & 0 \\
Home delivery & 354 & 90.8 & 0 \\
Institutional delivery & 333 & $85.40 \%$ & 0 \\
Is it easy to get PNC services? & & & \\
Distance from health institution (meter) & 92 & 23.6 & 0.924 \\
$<500$ & 219 & 56.2 & 0.0000 \\
500-2000 & 79 & 20.3 & 0.0000 \\
$>$ 2000 & 358 & 91.8 & 0.0000 \\
ANC follow-up & & & 0.8570 \\
Mode of delivery & 341 & 87.4 & 0.0000 \\
Spontaneous delivery & 23 & 5.9 & 0.578 \\
Cesarean section & 26 & 6.7 & 0.9980 \\
Instrumental delivery & 84 & 21.5 & 0.001 \\
$\begin{array}{l}\text { Presence of cultural reason } \\
\text { for not to go for PNC services }\end{array}$ & & & \\
Number of visits they know & & 32.6 & 0.995 \\
for PNC service & 126 & 34.8 & 0.994 \\
Once & 54 & & 0.0000 \\
Two to four & 143 & & \\
Four and above & & 36.7 & \\
\hline
\end{tabular}




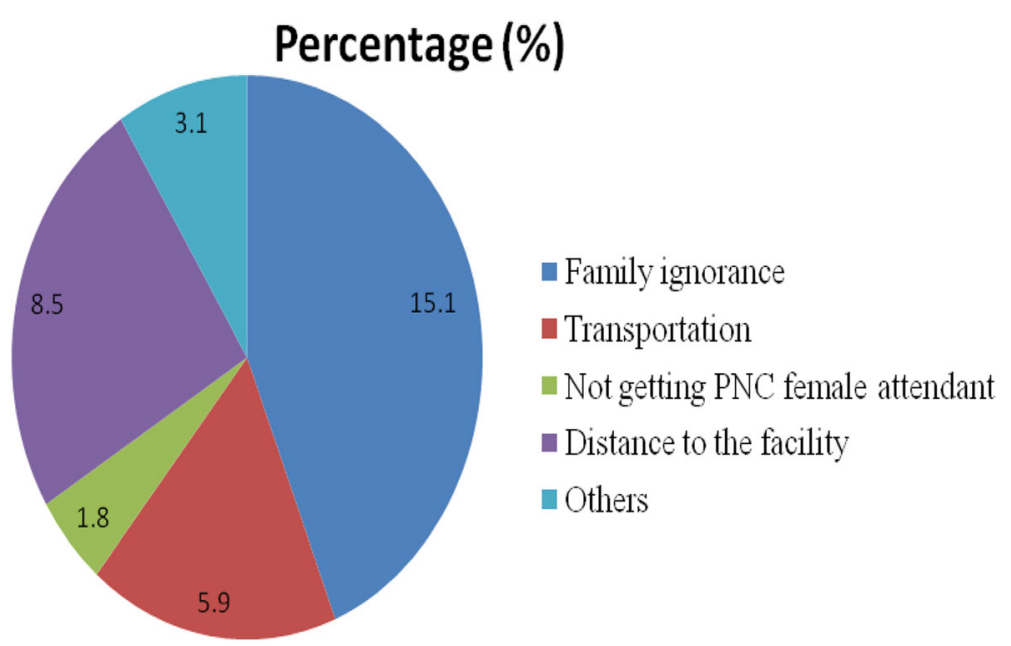

Fig. 2 Reasons for non-utilization of PNC in Debre Birhan Town

of the respondents $(219,56.2 \%)$ live a distance between 501 and $2000 \mathrm{~m}$ from their home to a nearby institution.

A large proportion of the mothers $(358,91.8 \%)$ had history of ANC follow-up and 341 (87.4\%) were delivered spontaneously. About 306 (78.5\%) answered no for presence of cultural barrier for not getting a PNC service (Table 3).

\section{Postnatal care service utilization}

Out of 390 women included in the study, 327 (83.8\%) had utilized postnatal care service in the last 1 year of which $143(36.7 \%)$ reported to have three or more postnatal visits at the time of the interview. Respondents gave different reasons for not getting a PNC visit.
Among the several reasons given, 59 (15.1\%) mentioned family ignorance (Fig. 2).

Nearly half $(173,44.4 \%)$ suggest the service must be improved, 158 (40.55) responded the PNC service must be nearby, and $163(41.8 \%)$ transport service must be improved to increase the utilization of PNC (Fig. 3).

\section{Socio-demographic, environmental, and clinical factors} Marital status, knowledge about PNC services, and place of birth has a significant association with PNC utilization. According to this study, a single mother was 0.06 times less likely to use PNC service than a married one [adjusted odds ratio $(\mathrm{AOR})=0.06,95 \% \mathrm{CI}$ $(0.01,0.45)]$ (Table 4).

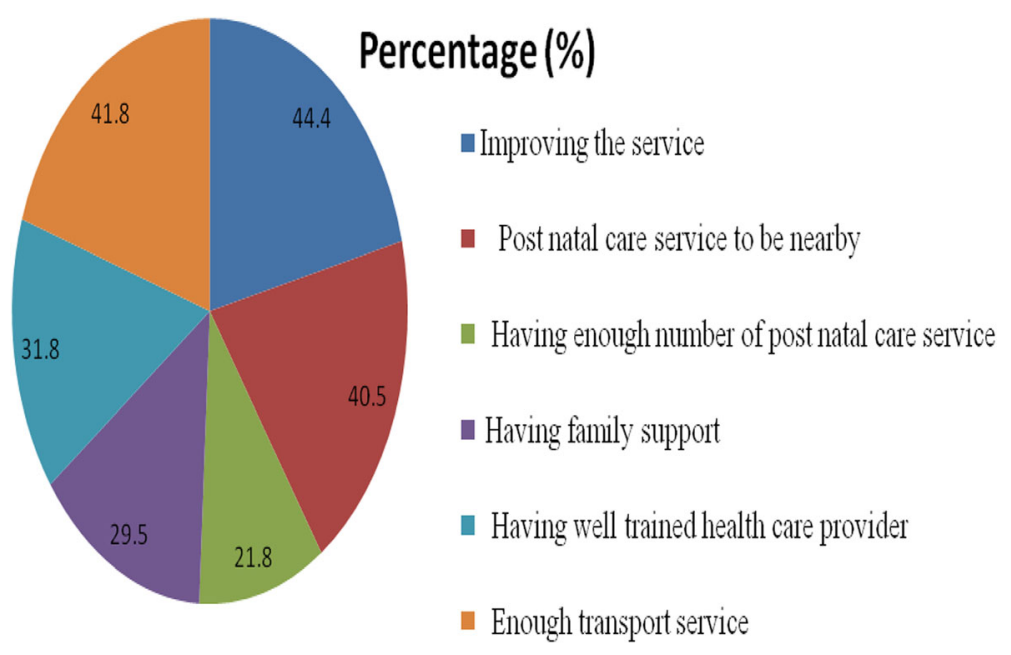

Fig. 3 Participants suggestion for improving the PNC service in Debre Birhan town 
Table 4 Socio-demographic factors associated with postnatal care utilization in Debre Birhan town, North Shoa, Ethiopia 2015 $(n=390)$

\begin{tabular}{|c|c|c|c|c|}
\hline \multirow[t]{2}{*}{ Variables } & \multicolumn{2}{|c|}{ PNC utilization } & \multirow{2}{*}{$\begin{array}{l}\text { Crude OR } \\
(95 \% \text { Cl) }\end{array}$} & \multirow{2}{*}{$\begin{array}{l}\text { Adjusted OR } \\
(95 \% \mathrm{Cl})\end{array}$} \\
\hline & No & Yes & & \\
\hline \multicolumn{5}{|l|}{ Maternal age } \\
\hline$<18$ & $12(13.3)$ & 78(86.7) & 1 & \\
\hline $18-24$ & $16(11.5)$ & $123(88.5)$ & $1.18(0.53,2.63)$ & \\
\hline $25-34$ & $20(20.8)$ & 78(79.6) & $0.60(0.27,1.31)$ & \\
\hline$\geq 35$ & 15(23.8) & $48(76.2)$ & $0.49(0.21,1.14)$ & \\
\hline \multicolumn{5}{|l|}{ Marital status } \\
\hline Married & $45(13.7)$ & 283(86.3) & 1 & 1 \\
\hline Single & 10(32.3) & $21(67.7)$ & $0.33(0.15,0.75)$ & $0.06(0.01,0.45)$ \\
\hline Divorced & $5(20.8)$ & 19(79.2) & $0.60(0.21,1.70)$ & $0.20(0.03,1.20)$ \\
\hline Widowed & $3(42.9)$ & $4(57.1)$ & $0.21(0.06,0.98)$ & $0.38(0.02,8.04)$ \\
\hline \multicolumn{5}{|c|}{ Maternal education } \\
\hline Illiterate & $19(42.2)$ & $26(57.8)$ & 1 & \\
\hline Grades 1-8 & $38(23.5)$ & $124(76.5)$ & $2.38(1.19,4.77)$ & \\
\hline Grades 9-12 & $6(4.9)$ & 116(95.1) & $14.1(5.13,38.8)$ & \\
\hline $12+$ & $0(.0)$ & $61(100)$ & $1.18(0.00)$ & \\
\hline \multicolumn{5}{|c|}{ Husband's education } \\
\hline Illiterate & $10(62.5)$ & $6(37.5)$ & 1 & \\
\hline Grades 1-8 & $35(29.4)$ & $84(70.6)$ & $4.00(1.35,1.85)$ & \\
\hline Grades 9-12 & $16(10.5)$ & $136(89.5)$ & $14.1(4.54,44.1)$ & \\
\hline $12+$ & $2(1.9)$ & $101(98.1)$ & $84.2(14.9473)$ & \\
\hline \multicolumn{5}{|l|}{ Monthly income } \\
\hline$<500$ & $37(34.3)$ & $71(75.7)$ & 1 & \\
\hline 500-1500 & $22(10.9)$ & 179(89.1) & $4.24(2.34,7.69)$ & \\
\hline $1500-2500$ & $4(6.7)$ & $56(93.3)$ & $7.30(2.45,21.68)$ & \\
\hline$>2500$ & $0(0.0)$ & $21(100.0)$ & $8.41(0.00)$ & \\
\hline
\end{tabular}

\section{Obstetric factors}

A significant association was found between the place of birth and PNC utilization. Mothers having institutional delivery were 0.65 times were more likely to utilize PNC services than those mothers who delivered at home $[\mathrm{AOR}=0.65,95 \% \mathrm{CI}(0.58,0.94)]$ (Table 5).

\section{Knowledge of mothers and PNC}

Mothers' knowledge have shown a significant association with utilization of PNC $[\mathrm{AOR}=0.03,95 \% \mathrm{CI}(0.00,0.44)$ ] (Table 6).

\section{Discussion}

In this study, it was learned that close to $84 \%$ of women sought at least one PNC from health institutions. This was consistent with a study done in Tigray in Adwa which was $78.3 \%$ [15] and another study done in Zimbabwe, $89.9 \%$ [20]. Our finding is contrary to much lower findings as evidenced by $66.83 \%$ [21], 51.4\% [22], $38.2 \%$ [23], 34.8\% [24], and 33.5\% [25] PNC utilization in Amhara region. The reason for the high level of utilization of maternal health services among urban women in our study compared with their rural counterparts is that in most sub-Saharan countries, urban women in Ethiopia tend to benefit from increased knowledge and access to maternal health services. Additionally, health facilities are more accessible in urban areas and the various health promotion programs that use urban-focused mass media work to the advantage of urban residents in close connection to the use of maternal health services [26].

In line with the hypothesis, the PNC service utilization rate in Debre Birhan town was higher than the 2011 national EDHS report. Thus, the town serves as an exemplary site for postnatal health care service provision. The high rate could be due to the implementation of diverse maternal health care service intervention initiatives designed to improve access. The increased utilization rate could also be due to a homogeneous nature of study participants as compared with diverse study subjects in the 2011 EDHS. Among the sociodemographic variables, marital status was the only variable which has a significant association with utilization of postnatal care. Accordingly, mothers who were single are less likely to utilize postnatal services than mothers who are married and live together with their husbands. Similarly, a study conducted in another part of the country reveals that married women are more likely to receive postnatal care services than unmarried women [27]. Married women who live together with their husbands could be supported by their husbands than single women.

This study revealed that a respondent's knowledge of postnatal care services is an important predictor of PNC utilization; accordingly, mothers who have knowledge of PNC services are more likely to utilize PNC than mother's who do not have knowledge on PNC services. This finding was consistent with the study done in Uganda that revealed among those who were aware of the PNC services, a large proportion of mothers utilized the services [28].

Women who had awareness/knowledge of the postnatal services did utilize the PNC service two times higher than those women who were not adequately informed about the PNC service. Similarly, a study done in northern Ethiopia found that those women who had got information about postnatal care services utilizes PNC and were more likely to attend a postnatal care service compared to those women who had got no information [14]. This finding may lead to a conclusion that the PNC service utilization is strongly influenced by the knowledge of women on postnatal care benefits. 
Table 5 Obstetric factors associated with PNC utilization among mothers in Debre Birhan town, North Shoa, Ethiopia, 2015 ( $n=390$ )

\begin{tabular}{|c|c|c|c|c|}
\hline \multirow[t]{2}{*}{ Variables } & \multicolumn{2}{|c|}{ PNC utilization } & \multirow{2}{*}{$\begin{array}{l}\text { Crude OR } \\
(95 \% \text { Cl) }\end{array}$} & \multirow{2}{*}{$\begin{array}{l}\text { Adjusted OR } \\
(95 \% \mathrm{Cl})\end{array}$} \\
\hline & No & Yes & & \\
\hline \multicolumn{5}{|c|}{ Age at 1st pregnancy } \\
\hline$<18$ & $6(26.1 \%)$ & $17(73.9 \%)$ & 1 & \\
\hline $18-35$ & $56(11.3 \%)$ & $309(84.7 \%)$ & $1.947(0.74,5.15)$ & \\
\hline 35 and above & $1(50 \%)$ & $1(50 \%)$ & $0.353(0.019,6.57)$ & \\
\hline Gravidity & & & 1 & \\
\hline 1 & 19(12.3\%) & $135(87.7 \%)$ & $0.7(0.39,1.28)$ & \\
\hline $2-4$ & $36(18.7 \%)$ & 179(83.3\%) & $0.229(0.084,0.62)$ & \\
\hline$\geq 5$ & $8(38.1 \%)$ & 13(61.9\%) & & \\
\hline \multicolumn{5}{|c|}{ Number of live births } \\
\hline 1 & 19(11.7\%) & $143(88.3 \%)$ & 1 & \\
\hline $2-4$ & $38(18 \%)$ & 173(82\%) & $0.605(0.34,1.09)$ & \\
\hline$\geq 5$ & $6(31.3 \%)$ & $11(64.7 \%)$ & $0.24(0.08,0.73)$ & \\
\hline \multicolumn{5}{|l|}{ Ever had abortion } \\
\hline Yes & $1(7.1 \%)$ & 14(92.9\%) & $2.57(0.33,20.04)$ & \\
\hline No & $62(16.5 \%)$ & $313(83.5 \%)$ & 1 & \\
\hline \multicolumn{5}{|l|}{ Ever had still birth } \\
\hline Yes & $4(40.0 \%)$ & $6(60 \%)$ & $0.276(0.075,1.007)$ & \\
\hline No & $59(15.5 \%)$ & $321(84.5 \%)$ & 1 & \\
\hline \multicolumn{5}{|c|}{ Ever had neonatal death } \\
\hline Yes & $59(15.6 \%)$ & $319(84.4 \%)$ & $2.703(0.79,9.27)$ & \\
\hline No & $4(33.3 \%)$ & $8(66.7 \%)$ & 1 & \\
\hline \multicolumn{5}{|l|}{ Place of birth } \\
\hline Home & $11(30.6 \%)$ & $25(69.4 \%)$ & 1 & 1 \\
\hline Health facility & $316(89.3 \%)$ & $38(10.7 \%)$ & $18.90(8.62,41.4)$ & $0.65(0.58,0.94)$ \\
\hline
\end{tabular}

Table 6 Knowledge-associated factors and PNC services among mothers in Debre Birhan Town, North Ethiopia, 2015 ( $n=390$ )

\begin{tabular}{|c|c|c|c|c|}
\hline \multirow[t]{2}{*}{ Variables } & \multicolumn{2}{|c|}{ PNC utilization } & \multirow{2}{*}{$\begin{array}{l}\text { Crude OR } \\
(95 \% \mathrm{Cl})\end{array}$} & \multirow{2}{*}{$\begin{array}{l}\text { Adjusted OR } \\
(95 \% \mathrm{Cl})\end{array}$} \\
\hline & Yes & No & & \\
\hline Heard about PNC service & $322(94.4 \%)$ & $19(5.6 \%)$ & $0.007(0.002-0.019)$ & \\
\hline Knowledge of the existence of PNC service & $321(95.3 \%)$ & $16(4.7 \%)$ & $0.005(0.002-0.014)$ & \\
\hline Knowledge on the danger signs during postnatal period & $322(95.5 \%)$ & $15(4.5 \%)$ & $0.005(0.002-0.014)$ & \\
\hline \multicolumn{5}{|l|}{ Knowledge on the PNC services } \\
\hline Yes & $317(96.9 \%)$ & $10(3.1 \%)$ & 1 & 1 \\
\hline No & $6(9)$ & $57(90.5)$ & $0.003(0.001,0.009)$ & $0.03(0.00,0.44)$ \\
\hline \multicolumn{5}{|l|}{ Distance from nearby health institution (meter) } \\
\hline$<500$ & $82(89.1 \%)$ & 10(10.9\%) & 1 & \\
\hline $501-2000$ & $196(89.5 \%)$ & $23(10.5 \%)$ & $1.039(0.474-2.228)$ & \\
\hline$>2001$ & $49(62 \%)$ & $30(38 \%)$ & $0.199(0.09-0.443)$ & \\
\hline ANC follow-up & $320(89.4 \%)$ & $38(10.6)$ & $0.033(0.013-0.082)$ & \\
\hline
\end{tabular}


According to this finding, the other significant variable which has an influence on utilization of PNC among the obstetric variables is place of delivery in which PNC services are found to be more likely utilized among mothers who gave birth at a health facility than mothers who gave birth other than a health facility. Similar findings were also reported in North Western Ethiopia [14, 22, 25] and elsewhere $[20,28,29]$.

\section{Strength and limitation of the study}

The finding of the study was sent to the Amhara health bureau and ministry of health that encourage the stake holders for interventional measurements on the awareness with the involvement of one of the authors by giving health education and training for health professionals and women in the community. The study design was a crosssectional which measures the exposure and outcome at the same time rather than a longitudinal design, so it is difficult to determine causal relationships between the proposed predictors and the outcomes of interest.

\section{Conclusion}

The magnitude of PNC service utilization in Debre Birhan town was higher when it is compared with EDHS data. Marital status, knowledge of the mothers on PNC service, and place of delivery were determinants of postnatal care service utilization. So priorities have to be given to maternal health services especially institutional delivery, since place of delivery is the major determinant of postnatal care utilization. Particular attention has to be given for women's education on health care issues; it is also recommended that better effort should be exerted to increase PNC utilization, by educating, motivating the public, and giving particular attention to mothers who are unmarried, divorced, and widowed.

\section{Abbreviations \\ AOR: Adjusted odds ratio; EDHS: Ethiopian demographic health survey; MDG: Millennium development goal; MMR: Maternal mortality rate; PNC: Postnatal care; SPSS: Statistical package for social science; WHO: World health organization}

\section{Acknowledgements}

We thank the North Shewa zone health bureau and Debre Birhan town health office for their participation in the study. We would like to also acknowledge the data collectors (midwives and nurses). We are also thankful to the mothers for participating in the study. Our final acknowledgement goes to Mr. Tekalign Nega for his thorough and intensive comments on the English language, grammar, proofing, and formats of the manuscript.

\section{Authors' contribution}

$\mathrm{BN}$ contributed to the concept of the study. BN, EG, and FS performed statistical analysis. BN and FS jointly wrote the draft of manuscript. FS and EG contributed in interpreting the result, literature review, and revising of the manuscript. All authors revised the manuscript and agreed on the findings and views expressed. All authors read and approved the final manuscript.

\section{Funding}

The paper is funded by Gondar University.

\section{Availability of data and materials}

The raw data of SPSS file under identification policy could be provided for a research purpose only, upon request via e-mail to the corresponding author.fitha2007@yahoo.com

\section{Ethics approval and consent to participate}

Ethical clearance was obtained from the Institutional Review Board of the University of Gondar. Permission was obtained from Debre Birhan Health Office and respective Kebeles. Informed written consent was obtained from each study respondent. Parental guidance letter was obtained for those participants having an age of 18 or less. Each respondent was informed about the objective of the study. They were also informed that all data obtained from them would be kept confidential.

\section{Competing interest}

The authors declare that they have no competing interests.

\section{Publisher's Note}

Springer Nature remains neutral with regard to jurisdictional claims in published maps and institutional affiliations.

\section{Author details}

${ }^{1}$ Department of Midwifery, College of Heath Science and Medicine, Wolaita Sodo University, Wolaita Sodo, Ethiopia. ${ }^{2}$ School of Public Health,

Department of Human Nutrition and Reproductive Health, College of Health Sciences and Medicine, Wolaita Sodo University, Wolaita Sodo, Ethiopia. ${ }^{3}$ Department of Medical Laboratory, College of Health Sciences and Medicine, Wolaita Sodo University, Po.box 138, Wolaita Sodo, Ethiopia. ${ }^{4}$ Department of Medical Laboratory, Wolaita Sodo University teaching referral Hospital, Wolaita Sodo, Ethiopia. ${ }^{5}$ School of Medicine, College of health science and Medicine, Wolaita Sodo University, Wolaita Sodo, Ethiopia.

Received: 21 August 2017 Accepted: 2 April 2018

Published online: 19 April 2018

\section{References}

1. WHO. Postpartum care of the mother and newborn: a practical guide $\mathrm{WHO} /$ RHT/MSM/983. Geneva: WHO; 1998.

2. Dhakal S, Chapman GN, Simkhada PP, Van ER, Stephens TJ, Raja AE. Utilization of postnatal care among rural women in Nepal. BMC Pregnancy Childbirth. 2007;7(19) https://doi.org/10.1186/1471-2393-7-19.

3. Babalola S, Fatusi A. Determinants of use of maternal health services in Nigeria-looking beyond individual and household factors. BMC Pregnancy Childbirth. 2009;9(43):1471-2393.

4. Lawn J, Kerber K. Opportunity for Africa newborns: practical data, policy and programmatic support for newborn care in Africa. Cape Town: PMNCH; 2006.

5. Kaso M, Addisse M. Birth preparedness and complication readiness in Robe Woreda, Arsi Zone, Oromia Region, Central Ethiopia: a cross-sectional study. Reprod Health. 2014;11:55. https://doi.org/10.1186/1742-4755-11-55.

6. Alkema L, Chou D, Hogan D, Zhang S, Moller AB, Gemmill A, et al. Global, regional, and national levels and trends in maternal mortality between 1990 and 2015, with scenario-based projections to 2030: a systematic analysis by the UN Maternal Mortality Estimation Inter-Agency Group. Lancet. 2016; 387(10017):462-74.

7. Rahman M, Haque SE, Zahan S. Factors affecting the utilization of postpartum care among young mothers in Bangladesh. Health Soc Care Community. 2011;19(2):138-47.

8. Central Statistical Agency [Ethiopia] and ICF International Ethiopia. Demographic and Health Survey 2011. Addis Ababa, Ethiopia and Calverton, Maryland: Central Statistical Agency and ICF International; 2012.

9. Wang W, Soumya A, Shanxiao W, Alfredo F. Levels and trends in the use of maternal health Services in Developing Countries. DHS Comparative Reports no. 26. Calverton, Maryland: ICF Macro; 2011.

10. Oluwaseyi SD. Determinants of postnatal care non-utilization among women in Nigeria.2014Cross ref.

11. Li XF, Fortney JA, Kotelchuck M, Glover LH. The postpartum period: the key to maternal mortality. Int J Gynaecol Obstet. 1996;54(1):1-10.

12. DiBari JN, Yu SM, Chao SM, Michael CL. Use of postpartum care: predictors and barriers. J Pregnancy. 2014;2014:530769. https://doi.org/10.1155/2014/ 530769. 
13. Jat TR, Nawi N, Sebastian MS. Factors affecting the use of maternal health services in Madhya Pradesh state of India. Int J Equity Health. 2011;10(59) https://doi.org/10.1186/1475-9276-10-59.

14. Workineh YG, Hailu DA. Factors affecting utilization of postnatal care service in Jabitena district, Amhara region, Ethiopia. Sci J Public Health. 2014;2(3): 169-76. https://doi.org/10.11648/.sjph.20140203.15.

15. Berhe H, Tilahun W, Aregay A, Bruh G, Gebremedhim H. Utilisation and associated factors of postnatal care in Adwa Town, Tigray, Ethiopia-a cross sectional study. Adv Res Pharmaceuticals Biologicals. 2013;3(1):353-9.

16. Worku AG, Yalew AW, Afework MF. Factors affecting utilization of skilled maternal care in Northwest Ethiopia: a multilevel analysis. BMC Int Health Human Rights. 2013;13(1) https://doi.org/10.1186/1472-698x-13-20.

17. Dagne E. Role of socio-demographic factors on utilization of maternal health care services in Ethiopia. 2010.

18. Ayele DZ, Belayihun B, Teji K, Ayana DA. Factors affecting utilization of maternal health care services in Kombolcha District, Eastern Hararghe Zone, Oromia Regional State, Eastern Ethiopia. Int Sch Res Not. 2014:(917058):1-8.

19. Stella B, Adesegun F. Determinants of use of maternal health services in Nigeria-looking beyond individual and household factors. BMC Pregnancy Childbirth. 2005;9:43.

20. Innocent $\mathrm{H}$, Seter S. Prevalence and associated factors for non utilization of post natal care service population based study in Kuwadzana peri-urban area, Zvimba, District of Mashonland West Province, Zimbabwe. Afr J Reprod Health. 1999;3(2):25-32

21. Tesfahun F, Worku W, Mazengiya F, Kifle M. Knowledge, perception and utilization of postnatal care of mothers in Gondar Zuria District, Ethiopia: a cross-sectional study. Matern Child Health J. 2014;18:2341-51. https:/doi.org/10.1007/s10995-014-1474-3 66.

22. Belachew T, Taye A, Belachew T. Postnatal care service utilization and associated factors among mothers in Lemo Woreda, Ethiopia. J Women's Health Care. 2016;5:318. https://doi.org/10.4172/2167-0420.1000318.

23. Abuhay M. Assessment of factors influencing utilization of postnatal care in Gondar Town North West of Ethiopia. Thesis. 2008;1-98. etd.aau.etd. institutional repository

24. Hordofa MA, Almaw SS, Berhanu MG, Lemiso HB. Postnatal care service utilization and associated factors among women in Dembecha District, Northwest Ethiopia. Sci J Public Health. 2015;3(5):686-92. https://doi.org/10. 11648/j.sph.20150305.24.

25. Postnatal care service utilization and associated factors among women who gave birth in the last 12 months prior to the study in Debre Markos Town, Northwestern Ethiopia: a community-based cross-sectional study. Int J Reprod Med. 2016;2016. https://doi.org/10.1155/2016/7095352.

26. Mekonnen Y, Mekonnen A. Utilization of maternal health care services in Ethiopia. Maryland: ORC Macro Calverton; 2002.

27. Prashant $\mathrm{S}$, Rajesh R, Manoj A, Lucky S. Determinants of maternity care services utilization among married adolescents in rural India. International Institute for Population Sciences. PLoS One. 2012;7(2):e31666. 10.1371.

28. Aminah $\mathrm{K}$. Factors determining utilization of postpartum care service in Uganda. hdi5; 2009. p. 1623u.

29. Nankwanga a. Factors influencing utilization of postnatal services in Mulago and Mengo hospitals Kampala, Uganda. 2004.

\section{Ready to submit your research? Choose BMC and benefit from:}

- fast, convenient online submission

- thorough peer review by experienced researchers in your field

- rapid publication on acceptance

- support for research data, including large and complex data types

- gold Open Access which fosters wider collaboration and increased citations

- maximum visibility for your research: over $100 \mathrm{M}$ website views per year

At BMC, research is always in progress.

Learn more biomedcentral.com/submissions 